\title{
Excess Fibroblast Growth Factor-7 (FGF-7) Activates $\beta$-Catenin and Leads to Ocular Surface Squamous Neoplasia in Mice
}

\author{
Chia-Yang Liu and Winston W.-Y. Kao \\ Edith J. Crawley Vision Research Center/Department of Ophthalmology, \\ College of Medicine/University of Cincinnati. Cincinnati OH
}

USA

\section{Ocular surface squamous neoplasia}

Human ocular surface squamous neoplasia (OSSN) is the most common ocular surface precancerous and cancerous lesion previously known by various names such as conjunctival intraepithelial neoplasia, corneal intraepithelial neoplasia (CIN), or both together (CCIN) (Grossniklaus et al., 1987). Clinically, OSSN manifests in different grades ranging from simple dysplasia to squamous cell carcinoma (Grossniklaus et al., 1987). Because of the high incidence of OSSN in the limbal area, where the corneal epithelial stem cells are located, the limbal transition zone/stem cell theory has been proposed for the development of CIN by Lee and Hirst (Lee and Hirst, 1995). Tseng and co-investigators have suggested that the slow cycling limbal stem cells may become hyper-proliferative by stimulations such as alterations in this anatomic site influenced by other factors, e.g., carcinogens, irradiation (eg, UVB), and the phorbol ester tumor promoter, 12-O-tetradecanoylphorbol 13-acetate (TPA) (Tseng, 1989), which can cause abnormal proliferation of the conjunctival and corneal epithelium and lead to the formation of CIN. Nevertheless, the etiology and pathogenesis of CIN and ocular surface carcinoma remain elusive. To date, there is no appropriate animal model available to study the molecular and cellular mechanisms of this disease. Therefore, the availability of such animal model will not only aid to understand the pathogenesis but also yield a more effective treatment for OSSN.

\section{Generation $\mathrm{Krt12}{ }^{r t T A} /$ tet-O-FGF-7 bi-transgenic mice and induction of FGF-7 overexpression by doxycycline}

It has been well documented that the mouse $\mathrm{Krt12}$ gene expression is restricted to the differentiated corneal epithelium (Liu et al. 1993, 1994). To generate a corneal epitheliumspecific and Dox-inducible transgenic driver mouse line, we have genetically introduced ("knock-in") an ires-rtTA (internal ribosome entry site-reverse tetracycline transactivator) cDNA into the 3'-untranslated region of themouse Krt12 gene locus via conventional genetargeting techniques (Chikama et al., 2005). The resulting transgenic mouse line was designated as $\mathrm{Krt12}{ }^{r t T A}$, in which like $\mathrm{K} 12$ expression pattern, the rtTA is constitutively and specifically expressed by the corneal epithelium. The Krt12rtTA mouse line was then crossed 
with the tetO-FGF-7 mouse line (a gift from Dr. Jeffrey Whitsett, Cincinnati Children's Hospital Medical Center, Tichelaar et al., 2000) to generate the Krt12rtTA/rtTA/tet-O-FGF-7 bitransgenic mouse strain. To induce FGF-7 expression, mice were injected once intraperitoneally with Dox $(80 \mu \mathrm{g} / \mathrm{g}$ body weight; Clontech Laboratories) dissolved in PBS (pH 7.4) at a concentration of $10 \mathrm{mg} / \mathrm{ml}$ and fed Dox-chow $(1 \mathrm{~g} / \mathrm{Kg}$ chow, Bioserv, Frenchtown, NJ). Control animals were fed regular chow. As shown in Figure 1, FGF-7 over-expression can be induced by doxycycline (Dox) induction and results in a phenotype resembling OSSN (Chikama et al., 2008). This bi-transgenic mouse line may serve as an animal model for understanding the relationship between signaling pathway and the pathological progression of this disease.

A.

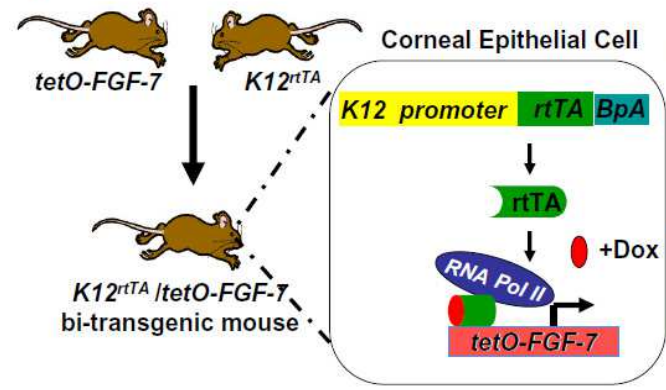

B.

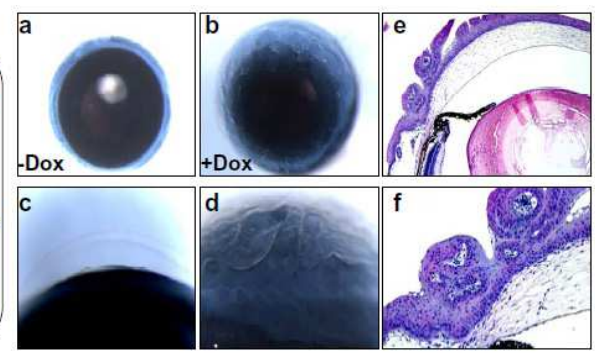

Fig. 1. Over-expression of FGF-7 resulted in OSSN in Cornea. A). Diagram showing that corneal epithelium-specific induction of FGF-7 by Dox in Krt12rtTA/rtTA/tetO-FGF-7 bitransgenic mice. B) K12rtTA /tetO-FGF-7 bi-transgenic mice exposed to Dox through mother fed doxycycline chow in the dam since post-nantal day1 (P1) showed corneal intra-epithelial neoplasia at P21 (Bb, Bd) compared to age-matched non-induced mice (Ba, Bc). Papillomalike epithelial lesion with mesenchymal invasion was found mainly in the peripheral/limbal region (Be, Bf).

\section{FGF-7 over-expression and ocular surface carcinogenesis}

FGF-7 is a potent mitogen for epithelial cells (Panos et al., 1993; Rubin et al., 1989). The pattern of expression of FGF-7 and its receptor suggest that FGF-7 serves as a paracrine produced by mesenchymal cells in modulating epithelial cells during embryonic development and the maintenance of homeostasis in adults (Finch et al., 1995). FGF-7 enhances epithelial cell proliferation in various organs (Finch et al., 1989, Rubin et al., 1995). Interestingly, aberrant up-regulation of FGF-7 has been reported to be associated with many human neoplastic tumors of epithelial cell origin (Cho et al., 2007; Manavi et al., 2007; Hishikawa et al., 2004; Mehta et al., 2000; Kovacs et al., 2006; Niu et al., 2007). Human papilloma virus 16 (HPV16) and long-term UV irradiation are the major risk factors for corneal intraepithelial neoplasia (Napora et al., 1990). Interestingly, it has been demonstrated that FGF-7 level within the cancer lesion was elevated throughout the progression of multi-stage epidermal carcinogenesis in K14-HPV16 transgenic mice (Arbeit et al., 1996; Pietras et al., 2008). It has been reported that the exposure to UVB irradiation can induce a rapid intracellular production of ROS (reactive oxidative stress), which in turn is 
capable of triggering phosphorylation and activation of the FGF-7 receptor, FGFR2-IIIb, similar to those induced by FGF-7 (Marchese et al., 2003). These results lead to our hypothesis that aberrant activation of FGF-7 signaling pathway(s) may be accountable for tumorigenesis derived from limbal stem cells that undergo oncogenic transformation by insults such as long-term UVB exposure and/or infection of HPV etc, which exhibit the characteristic phenotypes of OSSN (Scott et al., 2002; Karp et al., 1996; Kiire et al., 2006). The FGF-7/FGFR signaling is likely the hub that integrates the input through UVB and HPV with the genesis and formation of OSSN (Figure 2). This may explain why excess FGF-7 caused OSSN phenotype in the Dox-treated Krt12rtTA/rtTA/tet-O-FGF-7 bi-transgenic mouse model (Chikama et al., 2008).

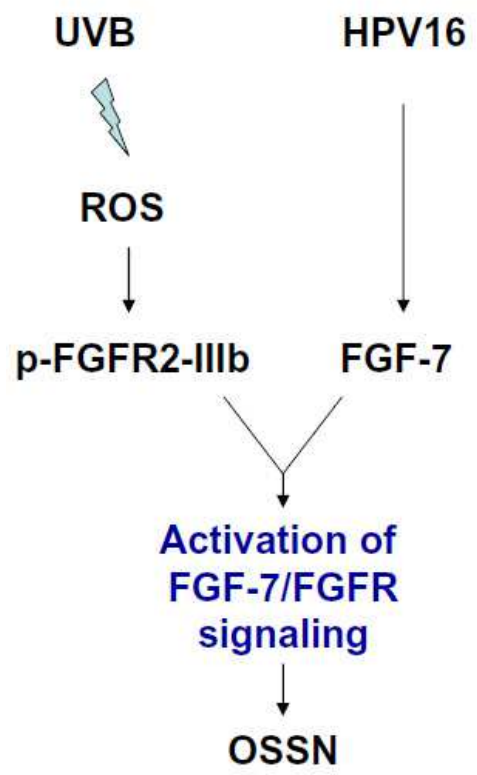

Fig. 2. Hypothetical schema showing that FGF-7/FGFR2 signaling can be activated by UVB and/or HPV type 16, two major risk factors for human OSSN. HPV16 transgene was known to be able to up-regulate FGF-7 (Artbeit et al., 1996). On the other hand, UVB can induced intracellular ROS which in turn phosphorylated and activated FGFR2-IIIb (Marchese et al., 2003). 
The precise spatio-temporal expression of FGF-7 is important for ocular surface tissue morphogenesis. FGF-7 are secreted by mesenchymal cells, which bind with high affinity to the same FGF receptor 2 (FGFR2-IIIb) isoform expressed mainly by the epithelial cells (Igarashi et al., 1998). In cornea, expression of FGF-7 and its cognate receptor FGFR2-IIIb is higher in limbal stroma and epithelium, respectively, than in the central cornea, implicating that FGF-7 may promote limbal stem cell proliferation and participate in modulation of corneal epithelium renewal and homeostasis (Li and Tseng, 1996, 1997). However, excess FGF-7 are capable of altering epithelial fates during embryonic development. For example, over-expression of FGF-7 driven by $\alpha$ A-crystalline promoter, which is activated in mouse lens at E11.5, resulted in the suppression of cornea-type epithelial differentiation and the induction of ectopic lacrimal gland formation in the corneas of the transgenic mice (Makarenkova et al., 2000; Govindarajan et al., 2000; Lovicu et al., 1999). In order to understand such an influence at a later stage when epithelial cells have undergone corneal type epithelial differentiation, we developed a $\mathrm{Krt12}{ }^{r t T A / r t T A} / t e t O-F G F-7$ bi-transgenic mouse line in which over-expression of FGF-7 by Dox induction caused squamous cell carcinoma of the cornea resembling OSSN in human (Chikama et al., 2008). Less is known, however, about the signaling pathways by which FGF-7 mediates control of corneal epithelial cell proliferation.

\section{FGF signaling pathway and its action in mammalian cells}

FGF signaling, which is involved in the control of cell proliferation, differentiation, migration, survival and polarity, is transduced through FGF receptors (FGFR). FGFR1, FGFR2, FGFR3 and FGFR4 are FGF receptors, consisting of an extracellular immunoglobulin-like (Ig-like) domain and a cytoplasmic tyrosine kinase domain (Lee et al., 1989; Dionne et al., 1990; Partanen et al., 1990, 1991; Powers et al., 2000; Katoh and Katoh, 2003). FGF receptor isoforms with distinct ligand affinity are generated by alternative splicing of mutually exclusive exons in the latter half of the third Ig-like domain. FGF dimers associated with heparan sulfate proteoglycan bind to FGF receptors to induce receptor dimerization and receptor auto-phosphorylation. FGF signals are transduced via multiple signaling pathways such as the mitogen-activated protein kinases (MAPK), the phospholipase-C gamma (PLC $\gamma$ ), and the PI3K-PKB/AKT (Eswarakumar et al., 2005; Dailey et al., 2005; Katoh and Katoh, 2006; Kouhara et al., 1997; Ong et al., 2000) (Figure 3). A key component of FGF signaling is the docking protein called FGFR substrate 2 (FRS2) which is phosphorylated on tyrosine residues upon FGF stimulation. FRS2 consists of N-terminal myristylation signal, phosphotyrosine binding (PTB) domain and C-terminal region with multiple Src homology-2 (SH2) binding sites. FRS2 is recruited to the autophosphorylated FGF receptors through the interaction with phospho-tyrosine residues. FRS2, bound to auto-phosphorylated FGFRs, is tyrosine phosphorylated in the C-terminal region, which in turns recruits growth factor receptor-bound protein 2 (GRB2) and a SH2containing tyrosine phosphatase, SHP2. In most cell types, FRS2-GRB2-SHP2 signaling complex recruits the guanine nucleotide exchange factor, Son of sevenless (SOS), which activates Ras and downstream effectors of MAPK (Figure 3, highlighted in grey). The MAPKs which include ERKs, p38, and Jun N-terminal kinases (JNKs) regulate the activity of downstream kinases or transcription factors. Although MAPK family shares many structural similarities, the ERK1/2 kinases are generally considered responsible for the 
mitogenic response, while the p38 and JNK are usually associated with inflammatory or stress-responses (Johnson et al., 2002).

Alternatively upon FGF stimulation, FRS2-SHP2-GRB2 complex may recruit GRB2associated binding protein 1 (GAB1) to activate PI3K (Figure 3, highlighted in yellow), which phosphorylates PIP2 to generate phosphatidylinositol-3,4,5-triphosphate (PIP3) (Ong et al., 2002; Cantley, 2002). PIP3 induces the translocation of PKB/AKT to plasma membrane, where $\mathrm{PKB} / \mathrm{AKT}$ is phosphorylated and activated by phosphoinositidedependent kinase (PDK) (Luo et al., 2003). The ability of FGFs to protect cells from apoptosis is primarily due to the activation of the PKB/AKT survival pathway, a PI3K dependent activation of PDK, leads to the activation of PKB/AKT which in turn attenuates the activity and/or suppression of pro-apoptotic factors (Schlessinger, 2000 Schlessinger. PKB/AKT phosphorylates a variety of substrates, such as glycogen synthase kinase (GSK-3 $\beta$ ), forkhead transcription factor (FKHR), FOXO1 (Burgering and Medema, 2003). It is of interest to note that inhibition of GSK-3 $\beta$ via phosphorylation its Ser-9 by activated PKB/AKT and provides additional anti-apoptotic protection (Jope and Johnson, 2004) and possibly the accumulation and nuclear translocation of $\beta$-catenin. Furthermore, a wide variety of agents, e.g., SB216763, SB-415286, and $\mathrm{LiCl}$, is known to attenuate GSK-3 $\beta$ activities via phosphorylation at Ser-9 by PKB/AKT and allow the accumulation and nuclear translocation of transcription factor $\beta$-catenin (Frame and Cohen, 2000).

FGF signal also activates phosphatidyl inositol (Pt Ins) hydrolysis, release of intracellular calcium and activation of protein kinase $\mathrm{C}$ (PKC) via recruitment of the $\mathrm{SH} 2$ domain of PLC $\gamma$ to the FGFR. Activated PLC $\gamma$ hydrolyzes Pt Ins [4,5] P2 to form diacylglygerol (DAG) and Ins $[1,4,5]$ P3 which stimulates calcium release and activation of calcium/calmodulin dependent protein kinases (Figure 3, highlighted in blue). The loss of this pathway does notappear to impair the proliferative response (Mohammadi et al., 1992). It remains unknown which individual aforementioned signaling pathways and/or their combination is responsible for the patho-physiology of OSSN caused by excess FGF-7 in our Krt12rtTA/rtTA/tet-O-FGF-7 mice.

\section{Cross-talk between FGF and Wnt pathways may be mediated by common target proteins}

It has been shown that FGF and Wnt signaling pathways crosstalk takes place during a variety of cellular processes, such as embryogenesis (Loebel et al., 2003; McGrew et al., 1997; Tickle, 1995; Ng, 2002; Villanueva et al., 2002; Gunhaga et al., 2003; Shackleford et al., 1993) and carcinogenesis (MacArthur et al., 1995; Katoh, 2002; McWhirter, 1997, 1999; Kirikoshi et al., 2000; Shimokawa et al., 2003; Chamorro et al., 2005; Katoh and Katoh, 2005). A key event in the canonical Wnt pathway is the activation of $\beta$-catenin that subsequently regulates transcription of specific target genes that modulate cell fate, proliferation, migration, and apoptosis. In the absence of Wnt signals, cytosolic $\beta$-catenin is phosphorylated by GSK-3 $\beta$, which targets $\beta$-catenin for proteasome-mediated degradation. However, in the presence of a Wnt signal, GSK-3 $\beta$ is inactivated by phosphorylation, and results in accumulation and nuclear translocation of stable $\beta$-catenin that binds DNA elements of members of the lymphoid enhancer factor/T-cell factor (LEF/TCF) family of transcription factors. Thus, it 
activates transcription of Wnt-target genes (Moon et al., 2002) (Figure 4). $\beta$-catenin also functions at the cell membrane where, as a component of the adherent junction, it links cadherin to the cytoskeleton (Kemler et al., 1993).

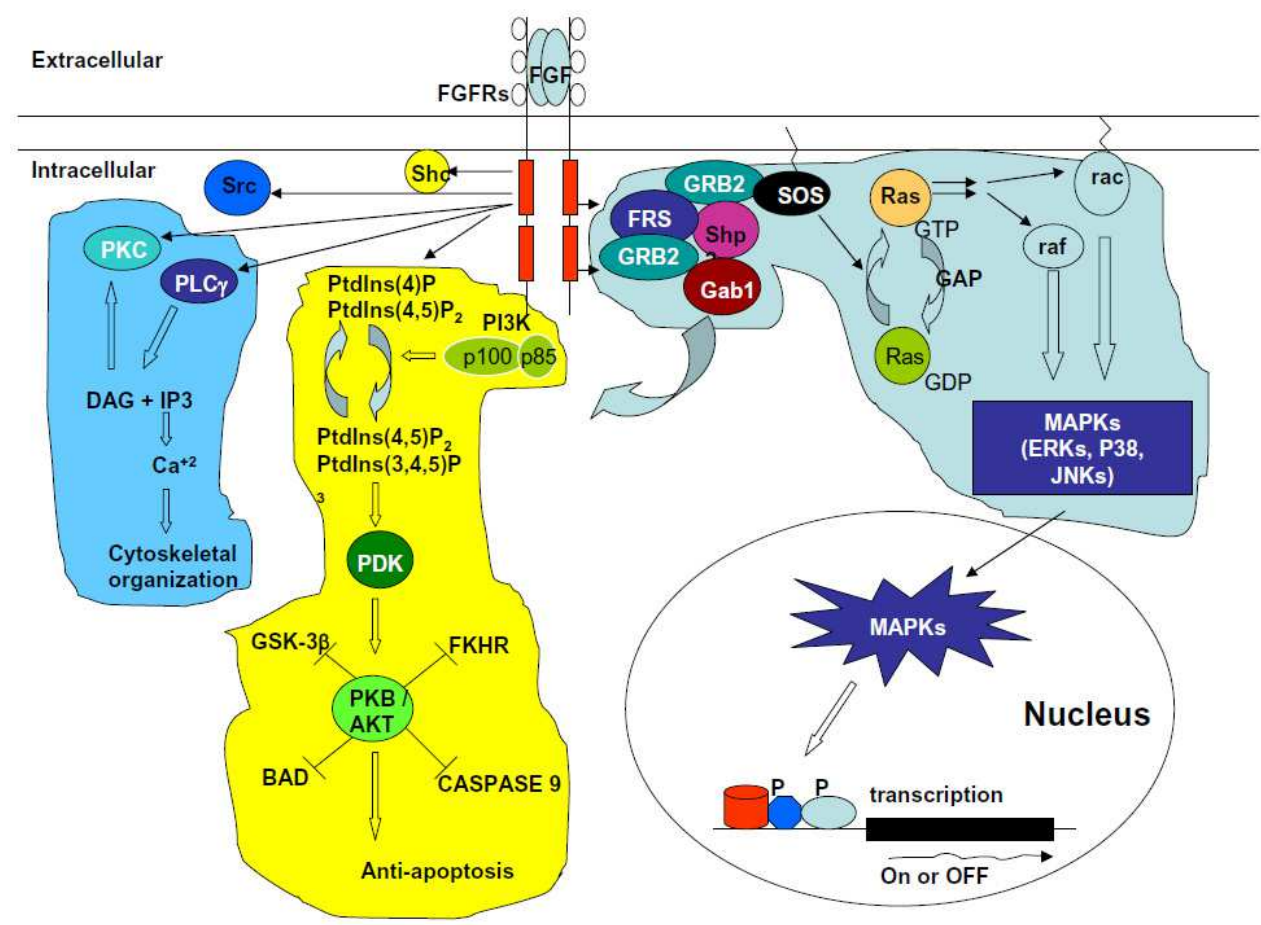

Fig. 3. FGF signal transduction pathways. Activated FGFRs (red rectangles) stimulate PLC $\gamma$ pathway (blue highlight), the PI3K/PKB-AKT pathway (yellow highlight), and the FRS2Ras-MAP kinase pathway (grey highlight). The activated MAP kinases (ERKs, p38, or JNKs) are translocated to the nucleus where they phosphorylate $(\mathrm{P})$ transcription factors, thereby regulating target genes. In some cell types, FGF signaling also phosphorylates the Shc and Src proteins. Abbreviations: PKB/AKT, protein kinase b; DAG, diacyl glycerol; ERKs, Extracellular signal-regulated kinases; FKHR, forkhead homolog 1; FRS2, Fibroblast growth factor receptor substrate 2; GAP, GTPase-activating protein; Gab1, Grb2-associated binding protein 1; GRB2, Growth factor receptor-bound protein 2; GSK-3 $\beta$, Glycogen synthase kinase 3 $\beta$;MAPK, Mitogen-activated protein kinase; JNKs, Jun N-terminal Kinases; PDK, 3phosophoinositide-dependent protein kinase;PI3K, Phosphoinositide 3-kinase; PKC, protein kinase C; PLC $\gamma$ : phospholipase C gamma; Rac, Ras-related C3 botulinum toxin substrate; Shp2, Src homology 2-containing tyrosine phosphatase; SOS, Son of sevenless, guanine nucleotide exchange factor. 

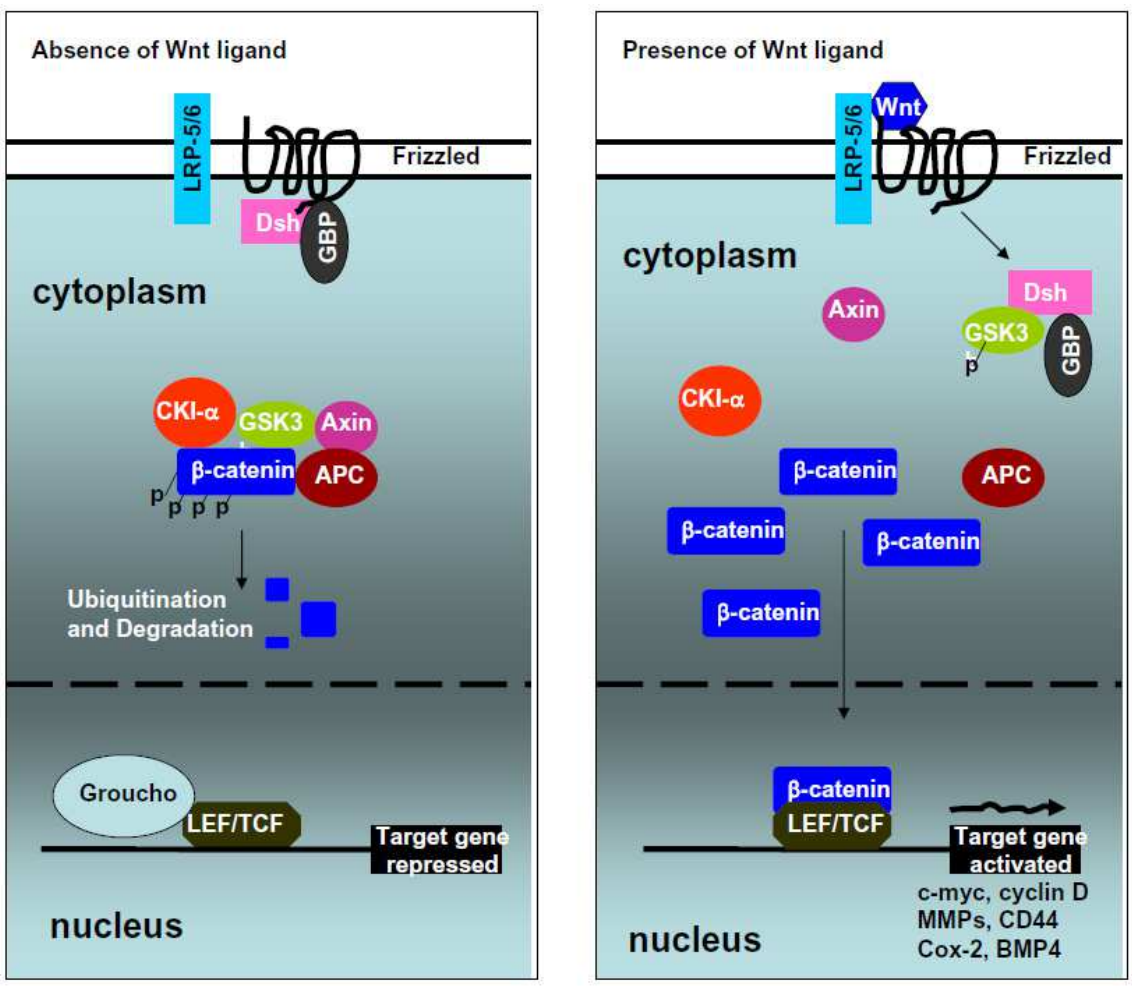

Fig. 4. Graphical depiction of the schema of the canonical Wnt signaling pathway. (Left panel) In the absence of Wnt ligand, LEF/TCF transcription factors are inert due to their association with a repressor (groucho protein) on their nuclear DNA binding sites. Betacatenin, which is needed for release of the repressor protein, is captured by a degradation complex containing casein kinase I alpha (CKI- $\alpha)$, GSK-3 $\beta$, Axin, and adenomatosis polyposis coli (APC) before it can enter the nucleus and is phosphorylated by GSK-3 $\beta$ and subsequently ubiquitinylated and degraded by the proteasome (Right panel). When Wnt ligand binds to its receptors, Frizzled and LRP5/6, dishevelled (Dsh) protein becomes activated. Repression of GSK-3 $\beta$ by an alternative complex containing Dsh and GSK-3 $\beta$ binding protein $(\mathrm{GBP})$ releases $\beta$-catenin from the aforementioned degradation complex. Unbound $\beta$-catenin enters the nucleus to complex with LEF/TCF, displacing groucho and enabling formation of an active transcription complex.

A possible candidate that can mediate both Wnt and FGF signalings is GSK-3 $\beta$, which can also be phosphorylated by PKB/AKT besides Dishevelled protein (Jope and Johnson, 2004). Evidence for this assertion has been provided during FGF-2 treatment of neuronal cells, which increases GSK-3 $\beta$ phosphorylation and nuclear localization of $\beta$-catenin. Overexpression of $\beta$-catenin maintains neural progenitor cells in a proliferative state in the presence of FGF-2, but enhances neuronal differentiation in the absence of FGF-2, suggesting that FGF signaling regulates neural progenitor cell proliferation and also affects lineage commitment during neural differentiation, in part, via $\beta$-catenin signaling (Israsena 
et al., 2004). Similarly, in neural cells, the neuroprotective effects of FGF-1 may utilize GSK$3 \beta$ inactivation via activation of the PI3K-PKB/AKT cascade (Hashimoto et al., 2002). In addition, FGF-2-treated human endothelial cells show an increase in nuclear $\beta$-catenin by a reduction in GSK-3 $\beta$ activity (Holnthoner et al., 2002). Although GSK-3 $\beta$ has been shown to be a phosphorylation target of FGF as well as other signaling pathways such as IGF, the consequences of altered GSK-3 $\beta$ activity on $\beta$-catenin/LEF/TCF-dependent transcription seems to be cell-type dependent. For example in 293 embryonic kidney cells, IGF-mediated phosphorylation of GSK-3 $\beta$ does not lead to induction of LEF/TCF-dependent transcription (Playford et al., 2000). During early Xenopus development, FGF signaling leads to the inhibition of endogenous GSK-3 $\beta$ via a PKB/AKT independent p90RSK pathway (Torres et al., 1999). p90RSK over-expression increases the level of membrane-associated $\beta$-catenin without fluctuation in nuclear levels. The fact that both FGF and Wnt signaling target a common protein implicates that the assignment of particular proteins such as GSK-3 $\beta$ to a specific "pathway" is arbitrary since their activity can be influenced by a number of different routes. Furthermore, since proteins such as GSK-3 $\beta$ are targeted by several signal transduction pathways, they have the potential to act as molecular switches between these pathways, and thus serve as nodal points for pathway cross-talk (Figure 5). In addition, GSK-3 $\beta$ also binds to and phosphorylates the SNAIL transcriptional repressor, inducing its cytoplasmic translocation and degradation (Zhou et al., 2004). SNAIL represses E-cadherin transcription, a key tight junction molecule which establishes and maintains cell-cell adhesion (Batlle et al., 2000; Katoh and Katoh, 2005; Thiery and Sleeman, 2006). Taken together, these data support a model whereby the inhibition of GSK-3 $\beta$ activity via FGFdependent PI3K-PKB/AKT signaling leads to an epithelial-mesenchymal transition (EMT) through the down-regulation of E-cadherin. This results in the release of $\beta$-catenin from the E-cadherin complex to promote nuclear accumulation of $\beta$-catenin. It remains unknown which aforementioned pathway is employed or in combination in the corneal epithelium elicited by excess FGF-7. Further investigation should lead to a clear mechanistic event of FGF-7 signaling in corneal epithelium and tumor formation.

\section{Nuclear accumulation of the $\beta$-catenin protein in tumors}

In human cancers, exon 3 of the CTNNB1 gene, which encodes $\beta$-catenin, is a mutational "hot spot" for gain-of-function isoforms. This exon encodes the critical Ser/Thr residues, which are sites for priming by casein kinase1 (CK1) (Ser 45) and phosphorylation by GSK-3 $\beta$ (Ser 33, 37 and Thr 41). As a result, this $\beta$-transducin repeat-containing protein $(\beta-\operatorname{TrCP})$ recognition site marks $\beta$-catenin for degradation. Therefore mutations within this exon increase the stability and nuclear accumulation of the $\beta$-catenin protein. Indeed, somatic mutations in CTNNB1 gene are strongly associated with a wide variety of human tumors including colorectal carcinoma, desmoid tumor, endometrial carcinoma, hepatocellular carcinoma, hepatoblastoma, intestinal carcinoma gastric, medulloblastoma, melanoma, ovarian carcinoma, pancreatic carcinoma, pilomatricoma, prostate carcinoma, squamous cell carcinoma of the head and neck, thyroid carcinoma, and Wilms' tumor (Polakis, 2000). To test the hypothesis that $\beta$-catenin accumulation in corneal epithelial cell nucleus plays a pivotal role in mediating FGF-7 signaling networks leading to the formation of corneal neoplasia in Krt12rtTA/rtTA/tetO-FGF-7 bi-transgenic mice induced by Dox, we have crossed K12rtTA/rtTA/tetO-FGF-7/tetO-Cre mice with two different floxed Ctnnb1 mouse strains for the 
analysis the role of $\beta$-catenin in corneal intraepithelial neoplasia model. In the first mouse line, loxP sites flank an essential part (exon 2 through exon 6) of the Ctnnb1gene (Ctnnb1 loxEx2-6) (Brault et al., 2001). Upon Cre-mediated recombination, the region containing exon 2 to 6 of the $C \operatorname{tnnb1}$ gene is deleted. This deletion causes a frame shift and premature termination of $\beta$-catenin translation. As a result, no $\beta$-catenin gene-product is produced from this allele. Interestingly, K12rtTA/rtTA/tetO-FGF-7/tetO-Cre/Ctnnb1 loxEx2-6/loxEx2-6 tetratransgenic mice treated with Dox from P7 to P21 (i.e., short term induction for 14 days) failed to develop corneal epithelial hyperplasia, suggesting that this phenotype caused by excess FGF-7 is dependent on $\beta$-catenin (Chia-Yang Liu et al., in preparation for publication).

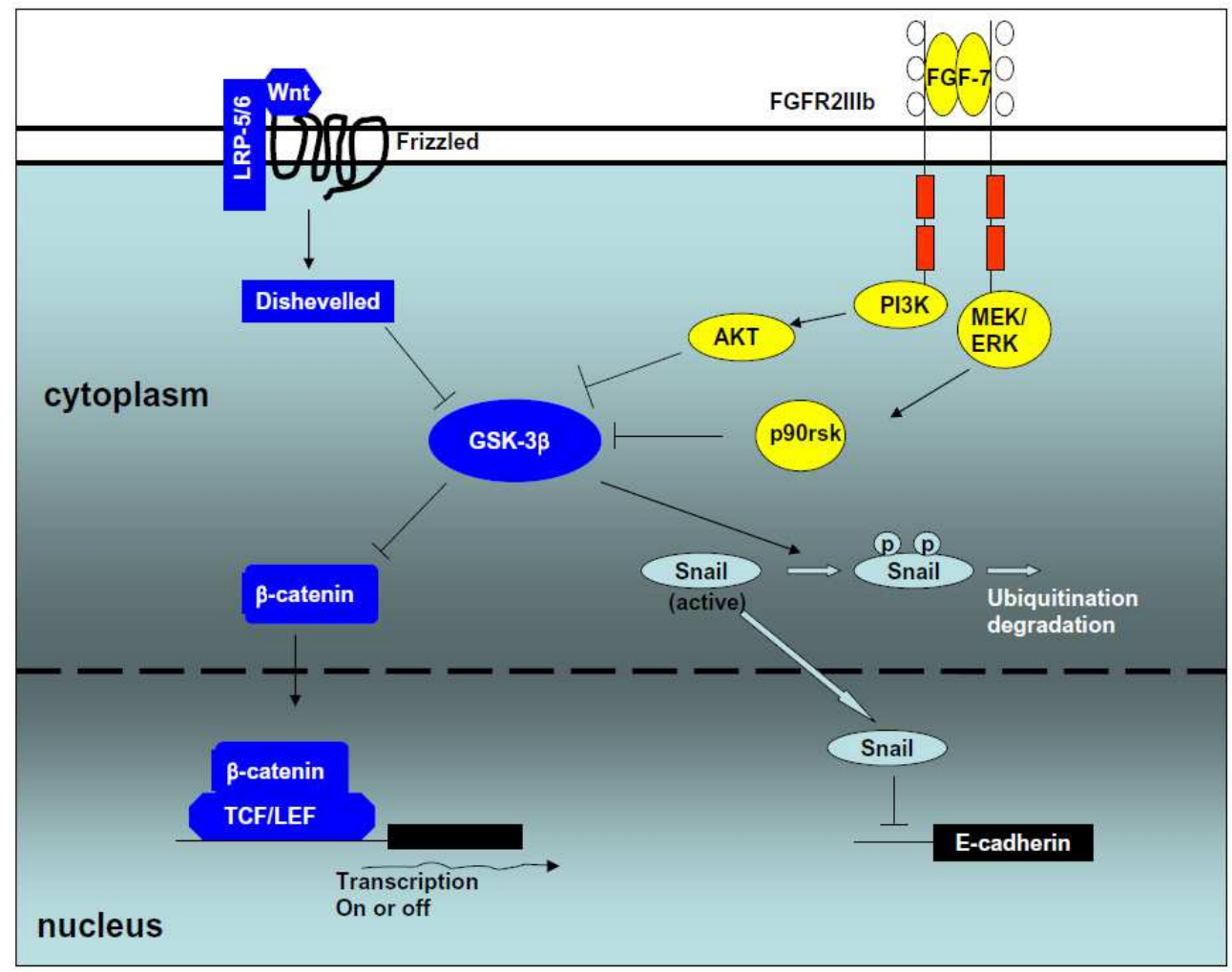

Fig. 5. Cross-talk between FGF and Wnt pathways. Elements of the FGF (yellow and red) and Wnt/ $\beta$-catenin (blue) pathways are shown. Depicted is how activation of the FGF receptor on the cell membrane can lead to activation of $\beta$-catenin through different mechanisms. In some cell types, activation by FGF of either PI3K/AKT or MAP kinase/p90 ribosomal S6 kinase (p90rsk) can promote GSK-3 $\beta$ phosphorylation, which is associated with translocation of $\beta$-catenin to the nucleus. Inhibition of GSK-3b by Wnt, PI3K/AKt, or MAPK pathways suppressed the phosphorylation of Snail (green) and thus induces the nuclear localization and protein stabilization of Snail, which suppress E-cadherin and lead to cell migration. 
In the second mouse line, loxP sites flank only exon 3 of the Ctnnb1gene (Ctnnb1floxedEx3) (Harada et al., 1999). Upon Cre-mediated recombination, exon 3 of the $\beta$-catenin gene is deleted. Exon 2 is spliced in frame to exon 4 and thus a mutant protein designated as $\Delta \mathrm{E} 3 \beta-$ catenin is produced. However, this mutant protein lacks its phosphorylation sites which are necessary for the subsequent ubiquitinylation and degradation of $\beta$-catenin. Therefore, this allele (Ctnnb1floxedEx3) encodes a more stable, constitutively dominant active $\beta$-catenin protein mimicking the canonical Wnt signaling pathway. Indeed, Dox-treated K12rtTA/wt/tetO-

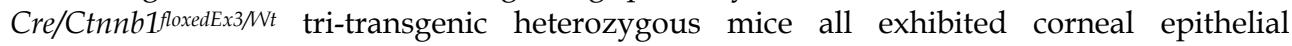
hyperplasia at different developmental stages from P1 to P30. Moreover, X-gal positive cells completely correlated with the hyperplastic transformation and stromal invasion in the

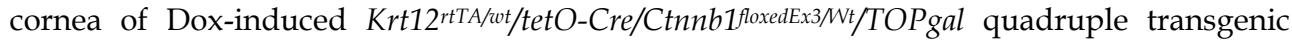
heterozygous mice (Zhang et al., 2010). These results strongly indicate that regulation of $\beta$ catenin signaling plays a pivotal role in the maintenance of normal corneal epithelial homeostasis.

\section{Pespective}

Cornea is a unique and idea model for study angiogenesis and tumor progression in vivo because of its transparency and easy accessibility. Cornea consists of three cellular layers i.e., epithelium, stroma, and endothelium providing an idea model to study epitheliummesenchym transition. In addition, corneal epithelium is also unique as a stratified but not keratinized epithelium, which allows us to study the epithelial metaplasia. Human OSSN consists of a spectrum of dysplasia and/or neoplasia which is relatively common in clinical ophthalmology practice. Primary surgical excision and various adjunctive therapies such as mitomycin-C (MMC), 5-fluorouracil (5-FU), or interferon alpha-2b (INF- $\alpha 2 b)$ remain as the mainstay of treatment but the recurrence rate is high. To improve the clinical outcome of OSSN treatment, agents aiming at the down regulation of signal transducing molecules that modulate $\beta$-catenin are required. It is anticipated that signal transduction molecule(s), e.g., ERK $\rightarrow$ p90RSK $\rightarrow$ GSK-3 $\beta \rightarrow \beta$-catenin and/or PI3K $\rightarrow$ PKB $/$ AKT $\rightarrow$ GSK- $3 \beta \rightarrow \beta$-catenin, which could mediate FGF-7 signaling networks responsible for the formation of corneal epithelial neoplasia will aid in the design of novel regimens for the treatment of human OSSN and other human cancers.

\section{Acknowledgment}

This work is supported by RO1 grants EY12486 (CYL), EY13755 (WWYK), and Research to Prevent Blindness

\section{References}

Arbeit, J.M., Olson, D.C. \& Hanahan, D. (1996). Upregulation of fibroblast growth factors and their receptors during multi-stage epidermal carcinogenesis in K14-HPV16 transgenic mice. Oncogene; 13:1847-1857

Batlle, E., Sancho, E., Franci, C., Dominguez, D., Monfar, M., Baulida, J. \& Garcia, De Herreros A. (2000) The transcription factor snail is a repressor of E-cadherin gene expression in epithelial tumour cells. Nat Cell Biol; 2:84-89. 
Brault, V., Moore, R., Kutsch, S., Ishibashi, M., Rowitch, D.H., McMahon, A.P., Sommer, L., Boussadia, O. \& Kemler, R. (2001) Inactivation of the beta-catenin gene by Wnt1Cre-mediated deletion results in dramatic brain malformation and failure of craniofacial development. Development; 128:1253-1264.

Burgering, B.M. \& Medema, R.H. (2003) Decisions on life and death: FOXO Forkhead transcription factors are in command when PKB/Akt is off duty. J Leukoc Biol ; 73:689-701.

Chamorro, M.N., Schwartz, D.R., Vonica, A., Brivanlou, A.H., Cho, K.R. \& Varmus, H.E. (2005) FGF20 and DKK1 are transcriptional target of b-catenin and FGF20 is implicated in cancer and development. EMBO J; 24:73-84.

Cantley, L.C. (2002) The phosphoinositide 3-kinase pathway. Science; 296:1655-1657.

Chikama, T., Hayashi, Y., Liu, C.Y., Terai, N., Terai, K., Kao, C.W., Wang, L., Hayashi, M., Nishida, T., Sanford, P., Doestchman, T. \& Kao W. (2005) Characterization of tetracycline-inducible double transgenic Krt12rtTA/+/tet-O-LacZ mice. Invest Ophthalmol Vis Sci. 46:1966-1972.

Chikama, T., Liu, C.Y., Meij, J.T.A., Hayashi, Y., Wang, I.J., Liu, Y., Nishida, T. \& Kao, W.W.Y. (2008) Excess FGF-7 in corneal epithelium causes corneal intraepithelial neoplasia in young mice and epithelium hyperplasia in adult mice. Am J of Pathol; 172:638-649.

Cho, K., Ishiwata, T., Uchida, E., Nakazawa, N., Korc, M., Naito, Z. \& Tajiri, T. (2007) Enhanced expression of keratinocyte growth factor and its receptor correlates with venous invasion in pancreatic cancer. Am J Pathol.; 170:1964-1974.

Dailey, L., Ambrosetti, D., Mansukhani, A. \& Basilico, C. (2005) Mechanisms underlying differential responses to FGF signaling. Cytokine Growth Factor Rev; 16:233-247.

Dionne, C.A., Crumley, G., Bellot, F., Kaplow, J.M., Searfoss, G., Ruta, M., Burgess, W.H., Jaye, M. \& Schlessinger, J. (1990) Cloning and expression of two distinct highaffinity receptors cross-reacting with acidic and basic fibroblast growth factors. EMBO J; 9:2685-2692.

Eswarakumar, V.P., Lax, I. \& Schlessinger, J. (2005) Cellular signaling by fibroblast growth factor receptors. Cytokine Growth Factor Rev; 16:139-149.

Finch, P.W., Rubin, J.S., Miki, T. \& Ron, D. \& Aaronson, S.A. (1989) Human KGF is FGFrelated with properties of a paracrine effector of epithelial cell growth. Science; 245:752-755.

Finch, P.W., Cunha, G.R., Rubin, J.S., Wong, J. \& Ron, D. (1995) Pattern of keratinocyte growth factor and keratinocyte growth factor receptor expression during mouse fetal development suggests a role in mediating morphogenetic mesenchymalepithelial interactions. Dev Dyn; 203:223-240.

Frame, S. \& Cohen P. (2000) GSK3 takes centre stage more than 20 years after its discovery. Biochem J; 359:1-16.

Govindarajan, V., Ito, M., Makarenkova, H.P., Lang, R.A. \& Overbeek, P.A. (2000) Endogenous and ectopic gland induction by FGF-10. Dev. Biol.; 225:188-200.

Grossniklaus, H.E., Green, W.R., Lukenback, M. \& Chan, C.C. (1987) Conjunctival lesions in adults: a clinical and histopathologic review. Cornea; 6:78-116.

Gunhaga, L., Marklund, M., Sjodal, M., Hsieh, J.C., Jessell, T.M. \& Edlund, T. (2003) Specification of dorsal telencephalic character by sequential Wnt and FGF signaling. Nat Neurosci; 6:701-707. 
Harada, N., Tamai, Y., Ishikawa, T., Sauer, B., Takaku, K., Oshima, M. \& Taketo, M.M. (1999) Intestinal polyposis in mice with a dominant stable mutation of the beta-catenin gene. EMBO J.; 18:5931-5942.

Hashimoto, M., Sagara, Y., Langford, D., Everall, I.P., Mallory, M., Everson, A., Digicaylioglu, M. \& Masliah, E. (2002) Fibroblast growth factor 1 regulates signaling via the glycogen synthase kinase-3beta pathway. Implications for neuroprotection. J Biol Chem; 277:32985-32991.

Hishikawa, Y., Tamaru, N., Ejima, K., Hayashi, T. \& Koji, T. (2004) Expression of keratinocyte growth factor and its receptor in human breast cancer: its inhibitory role in the induction of apoptosis possibly through the over-expression of Bcl-2. Arch Histol Cytol.; 67:455-464.

Holnthoner, W., Pillinger, M., Groger, M., Wolff, K., Ashton, A.W., Albanese, C., Neumeister, P., Pestell, R.G. \& Petzelbauer, P. (2002) Fibroblast growth factor-2 induces Lef/Tcf-dependent transcription in human endothelial cells. J Biol Chem; 277:45847-45853.

Igarashi, M., Finch, P.W. \& Aaronson, S.A. (1998) Characterization of recombinant human fibroblast growth factor (FGF)-10 reveals functional similarities with keratinocyte growth factor (FGF-7). J Biol Chem.; 273:13230-13235.

Israsena, N., Hu, M., Fu, W., Kan, L. \& Kessler, J,A. (2004) The presence of FGF2 signaling determines whether beta-catenin exerts effects on proliferation or neuronal differentiation of neural stem cells. Dev Biol; 268:220-231.

Johnson, G.L. \& Lapadat, R. (2002) Mitogen-activated protein kinase pathways mediated by ERK, JNK, and p38 protein kinases. Science; 298:1911-1912.

Jope, R.S. \& Johnson, G.V.W. (2004) The glamour and gloom of glycogen synthase kinase-3. Trends Biochem Sci; 29:95-102

Karp, C.L., Scott, I.U., Chang, T.S. \& Pflugfelder, S.C. (1996) Conjunctival intraepithelial neoplasia. A possible marker for human immunodeficiency virus infection? Arch Ophthalmol.;114:257-261.

Katoh, M. \& Katoh, M. (2003) FGFR2 and WDR11 are neighboring oncogene and tumor suppressor gene on human chromosome 10q26. Int J Oncol;22:1155-1159.

Katoh, M. (2002) WNT and FGF gene clusters. Int J Oncol ; 21:1269-1273.

Katoh, M. \& Katoh, M. (2005) Comparative genomics on FGF20 orthologs. Oncol Rep; 14:287-290.

Katoh, M. \& Katoh, M. Comparative genomics on SNAI1, SNAI2, and SNAI3 orthologs. Oncol Rep;14:1083-1086.

Katoh, M. \& Katoh, M. (2005) Comparative genomics on FGF8, FGF17, and FGF18 orthologs. In J Mol Med; 16:493-496.

Katoh, M. \& Katoh, M. (2005) Comparative genomics on FGF16 orthologs. Int J Mol Med; 16:959-963.

Katoh, M. \& Katoh, M. (2006) FGF signaling network in the gastrointestinal tract. Int J Oncol; 29:163-168.

Kemler, R. (1993) From cadherins to catenins: cytoplasmic protein interactions and regulation of cell adhesion. Trends Genet; 9:317-321.

Kiire, C.A. \& Dhillon, B. (2006) The aetiology and associations of conjunctival intraepithelial neoplasia. Br J Ophthalmol.; 90:109-113. 
Kirikoshi, H., Sagara, N., Saitoh, T., Tanaka, K., Sekihara, H., Shiokawa, K. \& Katoh, M. (2000) Molecular cloning and characterization of human FGF20 on chromosome 8p21.3-p22. Biochem Biophys Res Commun; 274:337-343.

Kouhara, H., Hadari, Y.R., Spivak-Kroizman, T., Schilling, J., Bar-Sagi, D., Lax, I. \& Schlessinger, J. (1997) A lipid-anchored Grb2-binding protein that links FGFreceptor activation to the Ras/MAPK signaling pathway. Cell ; 89:693-702.

Kovacs, D., Cota, C., Cardinali, G., Aspite, N., Bolasco, G., Amantea, A., Torrisi, M.R. \& Picardo, M. (2006) Expression of keratinocyte growth factor and its receptor in clear cell acanthoma. Exp Dermatol.; 15:762-768.

Lee, F.S., Lane, T.F., Kuo, A., Shackleford, G.M. \& Leder, P. (1995) Insertional mutagenesis identifies a member of the Wnt gene family as a candidate oncogene in the mammary epithelium of int-2/Fgf-3 transgenic mice. Proc Natl Acad Sci USA; 92:2268-2272.

Lee, G.A. \& Hirst, L.W. (1995) Ocular surface squamous neoplasia. Surv Ophthalmol; 39:429-450.

Lee, P.L., Johnson, D.E., Cousens, L.S., Fried, V.A. \& Williams, L.T. (1989) Purification and complementary DNA cloning of a receptor for basic fibroblast growth factor. Science; 245:57-60.

Li, D.Q. \& Tseng, S.C. (1996) Differential regulation of cytokine and receptor transcript expression in human corneal and limbal fibroblasts by epidermal growth factor, transforming growth factor-alpha, platelet-derived growth factor $B$, and interleukin-1 beta. Invest Ophthalmol Vis Sci; 37:2068-2080.

Li, D.Q. \& Tseng, S.C. (1997) Differential regulation of keratinocyte growth factor and hepatocyte growth factor/scatter factor by different cytokines in human corneal and limbal fibroblasts. J Cell Physiol; 172:361-372.

Liu, C.Y., Zhu, G., Westerhausen-Larson, A., Converse, R.L., Kao, C.W.C., Sun, T.T. \& Kao, W.W.Y. (1993) Cornea-specific expression of K12 keratin during mouse development. Curr Eye Res.; 12:963-974.

Liu, C.Y., Zhu, G., Converse, R.L., Kao, C.W.C., Nakamura, H., Tseng, S.C.G., Mui, M.M., Seyer, J., Justice, M.J., Stech, M.E., Hansen, G.M. \& Kao, W.W.Y. (1994) Characterization and chromosomal localization of the cornea- specific murine keratin gene Krt1.12. J Biol Chem.; 269:24627-24636.

Loebel, D.A., Watson, C.M., DeYoung, R.A. \& Tam, P.P. (2003) Lineage choice and differentiation in mouse embryos and embryonic stem cells. Dev Biol; 264:1-14.

Lovicu, F.J., Kao, W.W. \& Overbeek, P.A . (1999) Ectopic gland induction by lens-specific expression of keratinocyte growth factor (FGF-7) in transgenic mice. Mech. Dev; 88:43-53.

Luo, J., Manning, B.D. \& Cantley, L.C. (2003) Targeting the PI3K-Akt pathway in human cancer: Rationale and promise. Cancer Cell; 4:257-262.

MacArthur, C.A., Shankar, D.B. \& Shackleford, G.M. (1995) Fgf-8, activated by proviral insertion, cooperates with the Wnt-1 transgene in murine mammary tumorigenesis. J Virol ; 69:2501-2507.

Makarenkova, H.P., Ito, M., Govindarajan, V., Faber, S.C., Sun, L., McMahon, G., Overbeek, P.A. \& Lang, R.A. (2000) FGF10 is an inducer and Pax6 a competence factor for lacrimal gland development. Development; 127:2563-2572. 
Manavi, M., Hudelist, G., Fink-Retter, A., Gschwandtler-Kaulich, D., Pischinger, K. \& Czerwenka, K. (2007) Gene profiling in Pap-cell smears of high-risk human papillomavirus-positive squamous cervical carcinoma. Gynecol Oncol.; 105:418426.

Marchese, C., Maresca, V., Cardinali, G., Belleudi, F., Ceccarelli, S., Bellocci, M., Frati, L., Torrisi, M.R. \& Picardo, M. (2003) UVB-induced activation and internalization of keratinocyte growth factor receptor. Oncogene; 22:2422-24231.

McGrew, L.L., Hoppler, S. \& Moon, R.T. (1997) Wnt and FGF pathways cooperatively pattern antero-posterior neural ectoderm in Xenopus. Mech Dev; 69:105-114.

McWhirter, J.R., Goulding, M., Weiner, J.A., Chun, J. \& Murre, C. (1997) A novel fibroblast growth factor gene expressed in the developing nervous system is a downstream target of the chimeric homeodomain oncoprotein E2A-Pbx1. Development; 124:3221-3232.

McWhirter, J.R., Neuteboom, S.T., Wancewicz, E.V., Monia, B.P., Downing, J.R. \& Murre, C. (1999) Oncogenic homeodomain transcription factor E2A-Pbx1 activates a novel WNT gene in pre-B acute lymphoblastoid leukemia. Proc Natl Acad Sci USA; 96:11464-11469.

Mehta, P.B., Robson, C.N., Neal, D.E. \& Leung, H.Y. (2000) Serum keratinocyte growth factor measurement in patients with prostate cancer. J Urol; 164:2151-2155.

Mohammadi, M., Dionnem, C.A., Li, W., Li, N., Spivak, T. \& Honegger, A.M. (1992) Point mutation in FGF receptor eliminates phosphatidylinositol hydrolysis without affecting mitogenesis. Nature; 358:681-684.

Moon, R.T., Bowerman, B., Boutros, M. \& Perrimon, N. (2002) The promise and perils of Wnt signaling through beta-catenin. Science; 296:1644-1646.

Napora, C., Cohen, E.J., Genvert, G.I., Presson, A.C., Arentsen, J.J., Eagle, R.C. \& Laibson, P.R. (1990) Factors associated with conjunctival intraepithelial neoplasia: a case control study. Ophthalmic Surg.; 21:27-30.

Ng, J.K., Kawakami, Y., Buscher, D., Raya, A., Itoh, T., Koth, C.M., Rodriguez, Esteban. C., Rodriguez-Leon, J., Garrity, D.M., Fishman, M.C., Izpisua Belmonte, J.C. (2002) The limb identity gene Tbx5 promotes limb initiation by interacting with Wnt $2 b$ and Fgf10. Development; 129:5161-5170.

Niu, J., Chang, Z., Peng, B., Xia, Q., Lu, W., Huang, P., Tsao, M.S. \& Chiao, P.J. (2007) Keratinocyte growth factor/fibroblast growth factor-7-regulated cell migration and invasion through activation of NF-kappaB transcription factors. J Biol Chem.; 282:6001-6011.

Ong, S.H., Guy, G.R., Hadari, Y.R., Laks, S., Gotoh, N., Schlessinger, J. \& Lax, I. (2000) FRS2 proteins recruit intracellular signaling pathways by binding to diverse targets on fibroblast growth factor and nerve growth factor receptors. Mol Cell Biol; 20:979989.

Ong, S.H., Hadari, Y.R., Gotoh, N., Guy, G.R. \& Schlessinger, J. \& Lax, I. (2001) Stimulation of phosphatidylinositol 3-kinase by fibroblast growth factor receptors is mediated by coordinated recruitment of multiple docking proteins. Proc Natl Acad Sci USA; 98:6074-6079.

Panos, R.J., Rubin, J.S., Csaky, K.G., Aaronson, S.A. \& Mason, R.J. (1993) Keratinocyte growth factor and hepatocyte growth factor/scatter factor are heparin-binding 
growth factors for alveolar type II cells in fibroblast-conditioned medium. J Clin Invest; 92:969-977

Partanen, J., Makela, T.P., Alitalo, R., Lehvaslaiho, H. \& Alitalo, K. (1990) Putative tyrosine kinases expressed in K-562 human leukemia cells. Proc Natl Acad Sci USA; 87:89138917.

Partanen, J., Makela, T.P., Eerola, E., Korhonen, J., Hirvonen, H., Claesson-Welsh, L. \& Alitalo, K. (1991) FGFR-4, a novel acidic fibroblast growth factor receptor with a distinct expression pattern. EMBO J; 10:1347-354.

Pietras, K., Pahler, J., Bergers, G. \&, Hanahan, D. (2008) Functions of paracrine PDGF signaling in the proangiogenic tumor stroma revealed by pharmacological targeting. PLoS Med.; 5:e19

Playford, M.P., Bicknell, D., Bodmer, W.F. \& Macaulay, V.M. (2000) Insulin-like growth factor 1 regulates the location, stability, and transcriptional activity of beta-catenin. Proc Natl Acad Sci USA; 97:12103-12108.

Polakis, P. (2000) Wnt signaling and cancer. Genes Dev. 2000; 14:1837-1851.

Powers, C.J., McLeskey, S.W. \& Wellstein, A. (2000) Fibroblast growth factors, their receptors and signaling. Endocr Relat Cancer; 7:165-197.

Rubin, J.S., Osada, H., Finch, P.W., Taylor, W.G., Rudikoff, S. \& Aaronson, S.A. (1989) Purification and characterization of a newly identified growth factor specific for epithelial cells. Proc Natl Acad Sci USA; 86:802-806.

Rubin, J.S., Bottaro, D.P., Chedid, M., Miki, T., Ron, D., Cheon, G., Taylor, W.G., Fortney, E., Sakata, H., Finch, P.W. \& LaRochelle, W.J. (1995) Keratinocyte growth factor. Cell Biol. Intern.; 19:399-411.

Schlessinger, J. (2000) Cell signaling by receptor tyrosine kinases. Cell; 103:211-225.

Scott, I.U., Karp, C.L. \& Nuovo, G.J. (2000) Human papillomavirus 16 and 18 expression in conjunctival intraepithelial neoplasia. Ophthalmology.; 109:542-547.

Shackleford, G.M., MacArthur, C.A., Kwan, H.C. \& Varmus, H.E. (1993) Mouse mammary tumor virus infection accelerates mammary carcinogenesis in Wnt-1 transgenic mice by insertional activation of int-2/Fgf-3 and Hst/Fgf-4. Proc Natl Acad Sci USA; 90:740-744.

Shimokawa, T., Furukawa ,Y., Sakai, M., Li, M., Miwa, N., Lin, Y.M. \& Nakamura, Y. (2003) Involvement of the FGF18 gene in colorectal carcinogenesis, as a novel downstream target of the $\beta$-catenin/T-cell factor complex. Cancer Res; 63:6116-6120.

Thiery, J.P. \& Sleeman, J.P. (2006) Complex networks orchestrate epithelial-mesenchymal transitions. Nat Rev Mol Cell Biol ; 7:131-142.

Tichelaar, J., Lu, W.W. \& Whitsett, J.A. (2000) Conditional expression of fibroblast growth factor-7 in the developing and mature lung, J. Biol. Chem. 275: 11858-11864.

Tickle, C. (1995) Vertebrate limb development. Curr Opin Genet Dev; 5:478-484.

Torres, M.A., Eldar-Finkelman. H., Krebs, E.G. \& Moon, R.T. (1999) Regulation of ribosomal S6 protein kinase-p90(rsk), glycogen synthase kinase 3, and beta-catenin in early Xenopus development. Mol Cell Biol; 19:1427-1437.

Tseng, S.C.G. (1989) Concept and application of limbal stem cells. Eye; 3:141-157.

Villanueva, S., Glavic, A., Ruiz, P. \& Mayor, R. (2002) Posteriorization by FGF, Wnt, and retinoic acid is required for neural crest induction. Dev Biol; 241:289-301.

Zhang, Y., Call, M.K., Yeh, L.K., Liu, H., Kochel, T., Wang, I.J., Chu, P.H., Taketo, M.M., Jester, J.V., Kao, W.W. \& Liu, C.Y. (2010) Aberrant expression of a beta-catenin 
gain-of-function mutant induces hyperplastic transformation in the mouse cornea. J Cell Sci.; 123:1285-1294.

Zhou, B.P., Deng, J., Xia, W., Xu, J., Li, Y.M., Gunduz, M. \& Hung, M.C. (2004) Dual regulation of Snail by GSK-3b-mediated phosphorylation in control of epithelial mesenchymal transition. Nat Cell Biol; 6:931-940. 


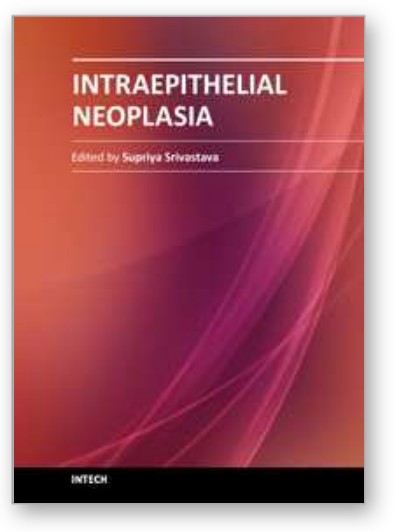

\author{
Intraepithelial Neoplasia \\ Edited by Dr. Supriya Srivastava
}

ISBN 978-953-307-987-5

Hard cover, 454 pages

Publisher InTech

Published online 08, February, 2012

Published in print edition February, 2012

The book "Intraepithelial neoplasia" is till date the most comprehensive book dedicated entirely to preinvasive lesions of the human body. Created and published with an aim of helping clinicians to not only diagnose but also understand the etiopathogenesis of the precursor lesions, the book also attempts to identify its molecular and genetic mechanisms. All of the chapters contain a considerable amount of new information, with an updated bibliographical list as well as the latest WHO classification of intraepithelial lesions that has been included wherever needed. The text has been updated according to the latest technical advances. This book can be described as concise, informative, logical and useful at all levels discussing thoroughly the invaluable role of molecular diagnostics and genetic mechanisms of the intraepithelial lesions. To make the materials easily digestive, the book is illustrated with colorful images.

\title{
How to reference
}

In order to correctly reference this scholarly work, feel free to copy and paste the following:

Chia-Yang Liu and Winston W.-Y. Kao (2012). Excess Fibroblast Growth Factor-7 (FGF-7) Activates b-Catenin and Leads to Ocular Surface Squamous Neoplasia in Mice, Intraepithelial Neoplasia, Dr. Supriya Srivastava (Ed.), ISBN: 978-953-307-987-5, InTech, Available from: http://www.intechopen.com/books/intraepithelialneoplasia/excess-fibroblast-growth-factor-7-fgf-7-activates-b-catenin-and-leads-to-ocular-surface-squamousneo

\section{INTECH}

open science | open minds

\author{
InTech Europe \\ University Campus STeP Ri \\ Slavka Krautzeka 83/A \\ 51000 Rijeka, Croatia \\ Phone: +385 (51) 770447 \\ Fax: +385 (51) 686166 \\ www.intechopen.com
}

\author{
InTech China \\ Unit 405, Office Block, Hotel Equatorial Shanghai \\ No.65, Yan An Road (West), Shanghai, 200040, China \\ 中国上海市延安西路65号上海国际贵都大饭店办公楼 405 单元 \\ Phone: +86-21-62489820 \\ Fax: $+86-21-62489821$
}


(C) 2012 The Author(s). Licensee IntechOpen. This is an open access article distributed under the terms of the Creative Commons Attribution 3.0 License, which permits unrestricted use, distribution, and reproduction in any medium, provided the original work is properly cited. 